\title{
PRÁTICAS DE ENSINO DE LITERATURA E DE LEITURA LITERÁRIA
}

\section{LITERARY READING AND TEACHING PRACTICES}

\author{
Gabriela Rodella de OLIVEIRA*
}

\begin{abstract}
Resumo: Este artigo apresenta possíveis didáticas para o ensino de literatura e de leitura literária em sala de aula no ensino superior, a partir da análise da proposta e da colocação em prática do Componente Curricular Ensino de Literatura e de Leitura Literária do curso de Licenciatura Interdisciplinar em Linguagens e suas Tecnologias da Universidade Federal do Sul da Bahia. O estudo baseia-se, também, na análise do percurso de formação da autora no ensino superior, assim como de pesquisas com professores de literatura da Educação Básica e com alunos do primeiro ano do Ensino Médio paulistano. Partindo dos conceitos de habitus (BOURDIEU) e de práticas (CHARTIER) e ancorado nas pesquisas sobre o ensino de literatura no Brasil e em didática da literatura de linha francesa, o artigo propõe uma reflexão sobre ações para a formação do leitor literário em um contexto sociocultural precário, no sentido de se garantir efetivamente a inclusão no ensino superior e uma posterior atuação desses sujeitos na educação básica.
\end{abstract}

Palavras-chave: Ensino de literatura. Formação do leitor. Leitura literária. Ensino superior. Educação básica.

Abstract: This paper presents possible didactics for teaching literature and literary reading in higher education based on the analysis of the proposal and the implementation of the curricular component Literature and Literary Reading Teaching, taught in the Interdisciplinary Degree in Languages and its Technologies course of the Federal University of South Bahia, Brazil. It is also draws on my personal experience as a higher education professor as well as on a research carried out with literature teachers in Basic Education and with high school students from São Paulo. Departing from the concepts of habitus (BOURDIEU) and practices (CHARTIER) and anchored in research on literature teaching in Brazil, the text proposes a reflection on the formation of literary readers in a specific socio-cultural context to effectively assure inclusion in higher education and later action of these subjects in basic education

Keywords: Literature teaching. Reader training. Literary reading. Higher education. Basic education.

\section{Introdução}

A IV Jornada de Literatura e Educação / I Simpósio Internacional de Literatura e Educação, ocorrida na Universidade Federal da Paraíba (UFPB) em agosto de 2019, propôs como tema de debate: "Literatura: aproximações entre a educação básica e o ensino superior". Buscando refletir sobre as práticas e metodologias na educação literária - do ensino básico ao ensino superior, me senti impelida a refletir sobre minha formação no bacharelado da Faculdade

\footnotetext{
* Professora Adjunta da Universidade Federal do Sul da Bahia (UFSB). Doutorado em Educação pela Universidade de São Paulo (USP). E-mail: gabirodella@gmail.com. ORCID: https://orcid.org/0000-0002-58221143.
} 
de Filosofia, Letras e Ciências Humanas da USP (FFLCH) e na licenciatura, no mestrado e no doutorado na Faculdade de Educação na mesma universidade (FE-USP), para compreender minha própria prática como formadora de professores em uma Licenciatura Interdisciplinar em Linguagens e suas tecnologias de uma Universidade Federal em território do interior do Sul da Bahia.

Quando iniciei minhas pesquisas acadêmicas sobre práticas de leitura literária e de ensino de literatura, o objeto escolhido foi a educação básica, mais precisamente o ensino de literatura no Ensino Médio. Como fica explícito em trabalhos dedicados à investigação da constituição da disciplina de Literatura no campo da educação básica brasileira, o ensino desta arte foi, a princípio, fundamentado por uma "concepção humanista"1 e implicou uma visão da literatura como "posse de um conhecimento erudito e de um patrimônio" (ZILBERMAN, 1988) e um “conjunto de modelos estéticos" (FREDERICO; OSAKABE, 2004), criado e consumido por classes sociais privilegiadas. A segunda metade do século XIX trouxe mudanças significativas para o ensino da disciplina. O conceito de literatura como conjunto de modelos persistiu, mas passou-se do trabalho com modelos estéticos da "concepção clássica" a "monumentos definidores das particularidades de uma língua e, via de regra, de uma nacionalidade" (FREDERICO; OSAKABE, 2004). Marisa Lajolo (1982) relata como José Veríssimo exigia em sua obra A educação nacional, de 1891, que o livro de leitura fosse "não só feito por brasileiro, que não é o mais importante, mas brasileiro pelos assuntos, pelo espírito, pelos autores transladados, pelos poetas reproduzidos e pelo sentimento nacional que o anime" (VERÍSSIMO, 1906, apud LAJOLO, 1982, p. 26). Paula Gregório Razzini (2000), em investigação do ensino de português e de literatura através da análise dos programas de ensino do Colégio Pedro II - escola secundária padrão fundada em 1837 - identifica que a literatura brasileira passa a constar do programa por volta de 1860 e, em 1892, entra para a grade escolar com o nome de "história da literatura nacional". Se, primeiramente, a literatura era um conhecimento que garantia a seus detentores uma distinção de classe ${ }^{2}$ (BOURDIEU, 2006), na

\footnotetext{
${ }^{1}$ Bourdieu, em análise publicada em 1968 como resultado de pesquisa realizada desde o início da década de 1960, discorre sobre uma "cultura 'desinteressada' da tradição humanista", afirmando que, "no seio de uma cultura clássica, todos os homens possuem em comum um mesmo tesouro de admiração, de modelos, de regras e, sobretudo de exemplos, metáforas, imagens, palavras, em suma, uma linguagem comum" (2005, p. 206). O sociólogo explica que o que "os indivíduos devem à escola [nessa tradição] é sobretudo um repertório de lugarescomuns, não apenas um discurso e uma linguagem comuns, mas também terrenos de encontro e acordo, problemas comuns e maneiras comuns de abordar tais problemas comuns" (p. 207).

${ }^{2}$ A "cultura humanista", à qual a elite teria acesso, funcionaria no sentido de unir os que a deteriam, além de servir também para diferenciá-los dos que não a teriam, funcionando como marca dessas elites: ela seria um luxo, um prazer que consagraria uma distinção (BOURDIEU, 2006).
} 
virada do século XIX para o XX, ela passa a ser também um conhecimento que garantia a construção de uma identidade nacional.

Em pesquisa com 87 professores do Ensino Médio (EM) da rede pública de São Paulo (OLIVEIRA, 2013a), cuja produção de dados foi realizada em 2006, eles indicavam trabalhar em sala de aula com a historiografia literária, com a leitura de resumos e com a avaliação de conhecimentos sobre períodos estéticos. À exceção de três professores entrevistados que trabalhavam com a leitura efetiva das obras e com sua análise em sala de aula, de diversas maneiras, movidos pela paixão que tinham por certos autores, resultado de uma formação e uma apropriação diferenciadas da literatura, a grande maioria dos sujeitos que participaram da pesquisa não chegava a tocar na literatura em si em sala de aula. Ou seja, a maioria dos professores que participou da pesquisa não trabalhava com a leitura efetiva do texto literário e não tinha como objetivo a formação de leitores, o que certamente tem relação com suas formações e suas apropriações do literário.

Antônio Augusto Gomes Batista, professor aposentado do Centro de Alfabetização, Leitura e Escrita (CEALE) da Faculdade de Educação da Universidade Federal de Minas Gerais (UFMG), publica em 1998 capítulo resultante de sua participação no I Seminário sobre leituras do professor, ocorrido na Universidade Estadual de Campinas (Unicamp), em 1997. Em seu texto, o pesquisador reproduz excertos de entrevistas com professores de Minas Gerais que explicitam as representações que eles próprios têm de si como leitores literários:

\footnotetext{
... dava vontade de gostar [de Guimarães Rosa]. Não sei ler Guimarães Rosa. Eu leio incerta. Eu leio muito incerta. Então, é uma coisa, assim, por exemplo, eu posso até ler e entender. Igual ao tal de Macunaíma, uma das melhores obras, eu estou engasgado com ele aqui. Eu não sei. Eu não tenho segurança de falar de Macunaíma na sala. Então, eu não sei, eu acho que não sei isso, sabe, acho que, quer dizer, até que se eu tivesse tempo ou lesse com alguém que entendesse, tudo muito bem, mas eu não sei, eu não sei. Eu leio e não sei se aquilo que eu sei é o que tinha que saber (BATISTA, 1998, p. 51, grifos do autor).
}

Diversos são os exemplos de leituras que explicitam uma relação tensa com a literatura considerada "legítima", marcadas pela ausência de autonomia na interpretação e pela busca de validação em leitores autorizados, resultantes de uma relação escolar com a leitura e descrevendo um processo de exclusão cultural.

$\mathrm{Na}$ sequência à investigação com os professores, trabalhei com 289 estudantes de primeiro ano do ensino médio de escolas particulares e públicas, também da cidade de São Paulo (OLIVEIRA, 2013b), cuja produção de dados se deu em 2010, buscando descrever suas práticas de leitura literária e as representações (CHARTIER, 1988) que tinham do que seria 
literatura e seu ensino. Foi possível perceber que eles liam, uns menos outros mais, a depender em parte do contexto social em que estavam inseridos, mas que liam outras coisas, não aquilo que a escola esperava que eles lessem. Há um trecho muito citado em pesquisas e trabalhos que investigam o ensino de literatura e a leitura de jovens e estudantes, em que o historiador Roger Chartier (1999, p. 103-104) afirma, em conversa com Jean Lebrun sobre as leituras dos jovens, que "aqueles que são considerados não leitores leem, mas leem coisa diferente daquilo que o cânone escolar define como uma leitura legítima". Contudo, quando a mediação do professor e a projeção do sujeito que é o estudante neste professor existem, a apropriação das leituras consideradas "legítimas" parece se tornar possível, como se percebe em resposta de uma estudante do Ensino Médio à pergunta sobre a dificuldade de se ler as leituras requisitadas pela escola:

\footnotetext{
Pergunta - Você acha que essas leituras são mais difíceis?

Catarina - É, porque normalmente essas leituras sempre têm uma metáfora por trás. Por exemplo, A ilha desconhecida ${ }^{3}$ o livro todo tem uma coisa por trás, porque senão seria um conto muito bobo, realmente. Então, tudo tem que ter uma análise, tudo você tem que parar para pensar. A primeira frase você tem de ler umas três vezes para entender, porque é muito difícil o jeito de ele escrever mesmo, porque ele coloca os diálogos junto das frases e aí você não sabe o que é diálogo e o que é o autor falando. Então, eu prefiro... Eu gosto muito de ler, mas eu prefiro, eu gosto de leituras fáceis. Não importa muito o tamanho, tipo tem 700 páginas, tudo bem. Só que leituras mais leves, assim... (OLIVEIRA, 2013b, p. 241).
}

Nessa relação e nessa apropriação residem a possibilidade da ampliação do repertório, do horizonte de expectativa, de representações do real, de sentidos outros que possam ser atribuídos ao que se vive, aspectos em geral relacionados à leitura da literatura.

\section{Anos de formação}

Cursei o bacharelado na Faculdade de Filosofia, Letras e Ciências Humanas da USP (FFLCH) e a licenciatura, o mestrado e o doutorado na Faculdade de Educação na mesma universidade (FE). No instituto de origem - a saber, a Faculdade de Letras -, cursávamos as disciplinas específicas; na FE, cursávamos as disciplinas pedagógicas. Desde a graduação, lembro-me de notar diferenças no que diz respeito às estratégias didáticas utilizadas nas aulas das duas faculdades. Acompanhei as aulas da professora Neide Luzia de Rezende por um longo período, de lugares institucionais distintos: primeiro como licencianda e, mais tarde, como monitora, tanto no curso de mestrado, como no de doutorado. Nesse período, chamava-me a

\footnotetext{
${ }^{3}$ O conto da ilha desconhecida, José Saramago, ed. Companhia das Letras, 1998. 
atenção o fato de que o habitus $^{4}$ (BOURDIEU; CHARTIER, 2011, p. 57-58) dos professores nas aulas das duas faculdades eram bastante diferentes, por razões que à época eram percebidas apenas intuitivamente, mas que diziam respeito ao tratamento dos conteúdos nas aulas, à preparação de uma discussão sobre um texto teórico, à participação dos alunos, aos trabalhos solicitados etc. Se as aulas na FFLCH pareciam estar fundadas no eixo do ensino, as aulas na FE-USP incluíam também o eixo da aprendizagem, pressupondo uma maior ocupação do espaço e do tempo em sala pela voz dos estudantes. Por essa razão, as aulas na Faculdade de Letras me pareciam pré-planejadas e regulares e as aulas na FE-USP tinham um ritmo que dependia da participação do alunado; pronunciar-se em aulas na FFLCH era um ato comedido, fazê-lo na FE-USP era algo obrigatório.

$\mathrm{Na}$ Faculdade de Letras, tive basicamente aulas expositivas ao longo de toda a minha formação, excetuando-se as aulas de língua alemã. Refletindo especificamente sobre as aulas de literatura brasileira, lembro-me das aulas do professor Alfredo Bosi, em que ele se sentava diante de um livro para cuja contracapa olhava com seus grossos óculos como se a estivesse lendo e relendo ao longo de duas horas, nas quais o ouvíamos, quase sem respirar, discorrer sobre a literatura quinhentista de modo lindamente articulado, e isso era maravilhoso. Lembrome também das aulas dos professores Alcides Celso Oliveira Villaça, Augusto Massi, Antônio Dimas de Moraes e José Miguel Wisnik, às quais também assistíamos quase paralisados. E me lembro de uma colega ter comentado um dia sobre seu desapontamento com as aulas de um professor: ela havia assistido a três de suas aulas no ano anterior, precisou trancar a matrícula, e recomeçou no ano seguinte, assistindo novamente às aulas que já havia tido, e descobriu que as aulas eram exatamente iguais. Ou seja, o professor preparava suas aulas e as ministrava de forma expositiva, fazendo os ajustes necessários, mas sempre a partir da mesma estrutura, por vezes com os mesmos comentários relativos à sua própria vida pessoal. Isso foi motivo de certo desapontamento, como se o fato de a reflexão e a análise de um conto de Guimarães Rosa não terem sido realizadas no exato momento da aula, as tornassem menos mágicas, algo próximo da cópia, algo pré-preparado. Como se o fato de a aula ser algo da ordem da performance, trouxesse em si um pouco da farsa que é a atuação de um ator e não o improviso de um leitor genial. Wille Bolle, que ministrava a disciplina de Literatura Alemã 5, lia seus textos em alemão ao longo das duas horas de curso; na realidade, ele nos dava palestras, uma a cada semana. $\mathrm{O}$

\footnotetext{
${ }^{4}$ Em conversa com Roger Chartier, Bourdieu percorre o que entende ser a gênese de seu conceito de habitus, remontando a Aristóteles e São Tomás de Aquino, passando por Husserl, Mauss, Durkheim e Weber, e significando que os "sujeitos" sociais não são "espíritos instantâneos" (BOURDIEU; CHARTIER, 2011, p. 57$58)$.
} 
querido professor Antonio Candido, em conferência na FE-USP em 2000, comentou que preparava também ele as suas aulas, escritas em cadernos arquivados em seu escritório, e que admitia que os alunos fizessem o que quisessem em sala, desde que ficassem em silêncio. Depois, comentou fazendo graça, que certo dia, uma senhorita sentada bem à sua frente decidiu fazer as unhas durante a aula. Incomodado, ele a advertiu, e ela lhe respondeu que ela estava em silêncio, obedecendo à regra instaurada por ele mesmo ao começo do curso. Ele riu. Em todas essas aulas, minha postura, e a da maioria de meus colegas, tinha como base o silêncio, a concentração e o desejo de apropriação de um discurso que muitas vezes cheguei a copiar em cadernos que guardo até hoje. Mas é preciso ressaltar que, quando cheguei à FFLCH, eu já era uma leitora de literatura.

Os exemplos acima são de professores já aposentados. Certamente há professores que trabalham de modo diverso em suas aulas atualmente na Faculdade de Letras da USP. A professora Vima Lia de Rossi Martin comentou, na ABRALIC de 2019, que suas aulas de literatura são sempre dialogadas. Contudo, conversando com um colega atualmente professor de Literatura Brasileira na mesma faculdade, ele me explicou que preferia seguir um roteiro já estabelecido de abordagem dos textos, para que nenhum detalhe se perdesse em uma fala espontânea. À pergunta sobre qual era a recepção e a percepção dos estudantes, ele respondeu rindo que algumas alunas comentavam que às vezes o ritmo das aulas era um pouco enfadonho...

Tendo tido aulas expositivas sobre Literatura, com análises teóricas elaboradíssimas - e não estou afirmando que essa seja uma má formação, pelo contrário, foi o que garantiu minha entrada na crítica literária e um modo pessoal de lidar com o literário -, quando cheguei à Faculdade de Educação, perguntava-me com certa ansiedade e um pouco angustiada o que exatamente eu trabalharia numa sala de aula de Ensino Médio (EM) de uma escola pública em que fui fazer estágio. Tive a certeza de que não teria condições de ministrar uma aula de historiografia literária por falta de formação para tal e, ao mesmo tempo, ao conversar com os alunos, a impressão era de que tais aulas não faziam sentido para eles. As chamadas disciplinas pedagógicas do curso de Licenciatura poderiam me ajudar a transpor para a educação básica o que eu havia aprendido por meio da leitura expert de meus professores? Esta era justamente a questão de meus estudantes na FE-USP, quando lá atuei como professora substituta ministrando a disciplina de Metodologia do Ensino de Língua Portuguesa I e II ao longo do ano de 2015. Conduzi-los nos debates sobre novas práticas e didáticas para a literatura foi possível graças à experiência da pesquisa com professores e alunos da educação básica sobre suas práticas e 
representações de leitura e de literatura, à participação no Grupo de Pesquisa Linguagens na Educação e ao contato com as investigações de Annie Rouxel, Gérard Langlade, Catherine Tauveron, Vincent Jouve, Marlène Lebrun, Max Butlen e todo um grupo de professores pesquisadores de uma nova didática de literatura em países de língua francesa.

\section{Didática para a literatura em uma Licenciatura Interdisciplinar em Linguagens}

\section{Contexto sociocultural no interior do sul do Estado da Bahia}

Trabalhando num contexto diferente do da USP, na Universidade Federal do Sul da Bahia (UFSB) instituição cuja entrada pelo Sistema de Seleção Unificada (Sisu) garante, além das cotas previstas pela Lei Federal no 12.711/2012 (Lei de Cotas), cerca de mais 10\% das vagas para ações afirmativas da própria Universidade (indígenas aldeados, ciganos, pessoas de comunidades remanescentes de quilombos ou de comunidades identitárias tradicionais, transexuais, travestis e transgêneros), recebemos estudantes cujo repertório de leitura literária é extremamente limitado. Trata-se de uma Universidade criada recentemente, prestes a completar seis anos de existência, ainda com muitas questões a serem resolvidas relativamente à sua implementação. Com altos índices de evasão por diversas razões, não é possível ministrar em um curso noturno aulas expositivas sobre um texto desconhecido de um autor desconhecido por três horas seguidas, pois o alunado, que chega ao Campus depois de um longo dia de trabalho e de longos deslocamentos em ônibus escolares pelas estradas da região, não teria condições de acompanhar uma estrutura de aula desse tipo. Além disso, por questões de organização da rotina de vida dos estudantes, em busca de que haja efetivamente inclusão: é preciso garantir que eles leiam em sala de aula; é preciso garantir que eles compreendam o que leem em sala de aula; é preciso garantir que eles tenham acesso às referências citadas no que eles leem em sala de aula.

$\mathrm{Na}$ outra ponta, mantendo contato constante com professores da educação básica da região. Acompanhamos quase 50 professores de Língua Portuguesa de Ensino Fundamental II (EF II), por meio de participação em curso de formação ofertado pela Secretaria de Educação do município, e acompanhamos professores de Língua Portuguesa do EM de escolas da região, em função do Componente Curricular de Estágio Supervisionado e do Programa de Residência Pedagógica, desenvolvido nos três campi da UFSB. O currículo definido pelos professores de EF II em jornada pedagógica e formativa em 2019 foi estruturado a partir exclusivamente de 
pontos gramaticais. Quando questionados sobre onde se encontraria a leitura, a literatura e a produção de textos, uma colega professora respondeu que tudo "se puxa" da gramática, que essas capacidades são ensinadas, que "todos sabem muito bem o que devem fazer". Porém, o que "se deve fazer" em relação a estes conteúdos e práticas não estava explícito no texto do currículo. Nas escolas estaduais, a historiografia segue sendo o esteio das aulas de Literatura, o que não é um problema em si, caso a leitura de textos também seja proposta. Foi a partir desta cronologia, indicada por uma colega com mais experiência e formada em Letras, que uma professora de Língua Portuguesa graduada em outra área se sentiu segura para conduzir suas aulas. Segundo ela, foi "uma luz", uma maneira de estruturar seu curso. Identificada com a fala da professora, revisitei minha ansiedade no início de minha formação, entendendo a necessidade de se ter uma organização para as aulas, a angústia de se lidar com um conteúdo e com uma turma de estudantes no início de uma prática docente, em busca de uma didática para a literatura. Como fazer?

Foi com esses professores que nossos licenciandos estudaram na educação básica, é com esses professores que eles fazem seus estágios supervisionados. Como levar para a sala de aula outras práticas, que não aquelas a que fomos submetidos como alunos, ou aquelas que observamos quando estagiamos? Tendo em vista essa situação, discorrerei sobre possíveis didáticas para o ensino de literatura e de leitura literária que temos colocado em prática no curso de Licenciatura Interdisciplinar em Linguagens e suas Tecnologias (LIL), em razão de um Projeto Pedagógico de Curso (PPC) de cuja elaboração participei como autora.

\section{Componente Curricular Ensino de Literatura e Leitura Literária}

O PPC da LIL da UFSB apresenta em sua página 5 o seguinte objetivo:

(...) garantir formação inicial, incluindo conhecimento, saberes e competências que permitam o/a estudante, quando licenciado/a, atender às novas demandas educacionais da sociedade brasileira na área de Linguagens e atuar na Educação Básica, favorecendo a construção de práticas inovadoras de formação docente, caracterizadas por metodologias integradoras e um permanente diálogo entre as áreas de conhecimento (UFSB, 2016, p. 5).

Os Componentes Curriculares (CCs) estão dispostos em três eixos, definidos da seguinte maneira:

a) Narrativas, registros e memórias

Os componentes curriculares ofertados neste eixo têm como objetivo levar o/a estudante a refletir sobre aspectos relacionados ao sujeito e à construção de sua 
subjetividade, à abertura para o outro em sua alteridade e em suas linguagens, às diversas representações construídas em narrativas e registros e aos diferentes espaços e tempos de circulação desses discursos. O conceito de memória é construído em um sentido amplo e plural, abrangendo diferentes vertentes teóricas, promovendo, desse modo, a consciência de si e do outro em uma perspectiva interdisciplinar. A meta é a formação do/a professor/a para a atuação consciente em um diálogo com as comunidades locais nas quais está inserido/a, partícipes de suas práticas sociais.

b) Multiletramentos

O segundo eixo, "Multiletramentos", a partir de uma concepção social da escrita, visa proporcionar ao/à estudante um conhecimento compartilhado sobre as possibilidades levantadas pela cibercultura no campo do letramento e da aprendizagem mediada pelas tecnologias intelectuais, levando-o/a a uma reflexão que possibilite uma ação transformadora não somente nas práticas pedagógicas no ensino superior e na educação básica, mas também no fazer técnico e/ou profissionalizante em outras modalidades que envolvem multiletramentos. Dessa forma, os CCs que fazem parte desse eixo envolvem, de forma integrada, três perspectivas formativas e interdependentes, a saber: a análise do contexto tecnológico contemporâneo, a cultura digital e a produção de conhecimento do/a professor/a.

Três são os encaminhamentos propostos pela Licenciatura Interdisciplinar em Linguagens e suas Tecnologias: inserir o/a estudante menos familiarizado/a aos usos das tecnologias digitais intelectuais da linguagem na prática docente; viabilizar situações proporcionadas por essas tecnologias de coexistência de espaços práticos de trabalhos próprios ao processo de ensino-aprendizagem; formar os/as estudantes para atuar profissionalmente em diversos campos que exijam práticas multiletradas.

c) Experiências Linguageiras

O terceiro eixo apresenta em seu fundamento uma aprendizagem ativa. Nos componentes curriculares presentes nesse eixo, os aspectos teóricos estão em profunda relação com a experimentação de práticas docentes, visando-se à desconstrução da oposição entre teoria e prática. Estão relacionados à criação de materiais e práticas voltados para o processo de ensino-aprendizagem, ao aprimoramento de métodos de ensino e ao desenvolvimento de estudos e práticas lúdicas (UFSB, 2016, p. 27-28).

Proposto dentro do eixo das Experiências Linguageiras como CC obrigatório, Ensino de Literatura e Leitura Literária tem em sua ementa a proposta de apresentar abordagens que possam abrir a possibilidade de desenvolvimento de outras didáticas para a literatura em sala de aula da educação básica. Previsto ainda como espaço para a problematização do cânone literário escolar, em nenhuma de suas ofertas pôde oferecer essa reflexão, tendo em vista que os estudantes, em geral, não trazem consigo a leitura ou mesmo o reconhecimento deste cânone. Neste sentido, na prática, o CC tornou-se um espaço para a formação de leitores literários de textos selecionados no cânone escolar que tinha como objetivo discutir. Dentre as possibilidades didáticas para a literatura discutidas no CC, algumas são praticadas em sala de aula no próprio curso (diagnóstico sobre as práticas de leitura dos estudantes, leitura em voz alta, debate interpretativo, roda de conversa sobre romances lidos, diário de leitura) e outras são apresentadas e apenas discutidas.

Conversas sobre as práticas de leitura dos estudantes 
Traçar um diagnóstico das práticas de leitura de estudantes na educação básica e no ensino superior é uma necessidade já apontada pela professora Lívia Ferreira (1970), da Universidade do Estado de São Paulo (UNESP), por Maria Thereza Fraga Rocco (1981) e Alice Vieira (1988), da FE-USP, e por Adilson Citelli (2004) ${ }^{5}$, da Escola de Comunicação e Artes da USP (ECA), para citar apenas alguns pesquisadores que investigaram o ensino de literatura e suas práticas em sala de aula e na escola. Trata-se de uma prática há muito defendida em investigações acadêmicas e que busco levar para a sala de aula na educação básica e no ensino superior sempre que a literatura é objeto de ensino-aprendizagem.

Em uma aula sobre Vidas Secas em uma turma do cursinho do Programa Pré-Vestibular da Universidade de São Paulo - PPVUSP, financiado a estudantes de escolas públicas pela Reitoria da Universidade em 2012, a leitura de um capítulo do livro, considerada chata e lenta, só foi possível depois de um debate e um levantamento sobre o que interessava aos jovens nas leituras de aventura que eles faziam por conta própria - que, à época, eram leituras de livros de aventura, como Harry Potter, Percy Jackson etc. A partir daí, por comparação entre as caraterísticas das obras, a leitura de Graciliano pôde ser identificada com uma possibilidade de reflexão pelos próprios estudantes e o narrador, em discurso indireto livre, pôde ser compreendido como o porta-voz de personagens que não podiam falar, em análise elaborada por eles. Roger Chartier (1999, p. 103-104) observa que é “(...) preciso utilizar aquilo que a norma escolar rejeita como um suporte para dar acesso à leitura na sua plenitude, isto é, ao encontro de textos densos e mais capazes de transformar a visão do mundo, as maneiras de sentir e de pensar". Em seu texto "Por uma literatura brasileira de entretenimento", José Paulo Paes defende que "nenhuma cultura realmente integrada pode se dispensar de ter, ao lado de uma vigorosa literatura de proposta, uma não menos vigorosa literatura de entretenimento" (PAES, 1990, p. 37), pois entende que é justamente dos leitores desta última que podem surgir os leitores daquela.

\section{Memoriais de leitura}

Além das conversas sobre suas leituras pessoais, trabalhamos com a leitura e a escrita de memoriais dos estudantes sobre seus percursos escolares e de formação como leitor. Trata-se

\footnotetext{
${ }^{5}$ Coordenada por Lígia Chiappini Moraes Leite e dividida em três subgrupos sob a responsabilidade de Adilson Odair Citelli, Guaraciaba Micheletti e Helena Nagamini Brandão, João Wanderley Geraldi e Beatriz Helena Marão Citelli, a pesquisa foi pensada e desenvolvida em duas etapas ( $1^{a}$ de 1992 a 1994; $2^{a}$ de 1996 a 1998) e teve apoio do CNPq e da Fapesp. Os resultados dos trabalhos foram publicados nos três primeiros volumes da série Aprender e ensinar com textos, publicada pela Editora Cortez, de São Paulo, que atualmente já se encontra no décimo primeiro volume.
} 
de uma proposta de autodescrição (BRUNER; WEISSER, 1995), a partir da qual o caráter interpretativo e de reconstrução da memória pode ser explicitado. Para esses autores (1995, p. 149), “a função última da autobiografia é a autolocalização, o resultado de um ato de navegação que fixa a posição em um sentido mais virtual que real”, por meio do qual o sujeito pode se situar no mundo simbólico da cultura, identificando-se com uma família, com uma comunidade, construindo um sentido para sua existência. Por meio da escrita de memoriais buscamos abrir espaço para que a constituição de sujeitos leitores possa acontecer, a partir das relações com os livros e experiências de leitura relatadas, mesmo que precárias. E os resultados são visíveis ao final da graduação, quando estudantes que liam muito pouco relatam sobre suas leituras, seguem pedindo indicações de livros e compartilham experiências de leitura e de ensino de leitura que extrapolam sua estada na Universidade.

\section{Roda de conversa, círculo de leitura, comitês de leitura}

Com rodas de conversa sobre livros lidos, ou "comitês de leitura", conforme descreve Marlène Lebrun (2013, p. 140), abre-se espaço para que os alunos selecionem os livros que querem ler, que os leiam, que escrevam notas críticas sobre essas leituras e que as apresentem oralmente, justificando o fato de terem gostado ou não das leituras que fizeram a partir de critérios que vão sendo construídos coletivamente.

A proposta de Lebrun favorece a emergência e o choque das subjetividades de leitores da pré-escola ao EM graças a um espaço interpretativo que é aberto a partir de quatro etapas: 1) leitura como um encontro singular e pessoal; 2) escrita de primeiras impressões de leitura sob forma de notas; 3) discussão, trocas, formulação e justificação de julgamentos de gosto; 4) regulação, avaliação do benefício e do funcionamento dos comitês de leitura.

Lebrun (2013, p. 140), afirma que, "se entendemos a leitura plural como intrínseca à leitura literária, podemos declinar, ao infinito, as ações implicadas na leitura: trocar, cooperar, caminhar, caçar, apropriar-se, descentrar-se, julgar, escolher, ligar...”. E esta abordagem dos textos literários seria "capaz de situar um em relação ao outro e de provocar o conflito interpretativo, [que] faz da leitura literária uma crítica no sentido etimológico do termo, 'ação ou faculdade de distinguir, escolher, decidir, julgar"' o que agrada, o que convém, o que se quer ler.

Chartier também destaca a importância da comunidade quando pensamos nas apropriações possíveis por meio da leitura. Para o historiador, "cada leitor, para cada uma de suas leituras, em cada circunstância é singular. Mas esta singularidade é ela própria atravessada 
por aquilo que faz que este leitor seja semelhante a todos aqueles que pertencem à mesma comunidade" (CHARTIER, 1999, p. 91-92).

A aprendizagem da leitura é importante também porque permite a construção de uma "biblioteca pessoal", espécie de "enciclopédia do leitor", e de uma "biblioteca coletiva do grupo", que permite discutir textos, interpretações e análises. As referências comuns, a biblioteca coletiva e o repertório de leitura comum tornam-se a base de um intercâmbio cultural que permite negociações culturais e pactos interpretativos.

Tenho muitos estudantes evangélicos, que chegam à Universidade como leitores intensivos (CHARTIER, 1999) da Bíblia. Em uma roda de conversa provocada no CC, o fato de terem acesso a outros tipos de livros - como a leitura de Capão Pecado, de Férrez, realizada por um estudante indígena adventista, ou de Ainda estou aqui, de Marcelo Rubens Paiva, por uma estudante sabatista que se identifica tanto com o livro, em função de sua experiência com seu avô, que cai no choro falando sobre ele em sala de aula - traz à tona experiências singulares que passam a fazer parte do repertório da comunidade formada pelos estudantes, o que amplia seus horizontes de leitura.

\section{Leitura em voz alta em sala de aula}

Seria de se esperar que a escola formasse leitores capazes de ler tanto em voz alta como silenciosamente, mas em nossa experiência são poucos os estudantes leitores adultos capazes de ler bem um texto em voz alta. A maioria não teve a oportunidade de praticar esse tipo de leitura em público, nem em um território em que a força da oralidade é algo muito visível. Trata-se de um trabalho difícil, uma atividade que supõe treinamento e interpretação, emprego de estratégias de ação, domínio da melodia, de impostação, de modulação da voz, do corpo. Mas tampouco a leitura silenciosa funciona tranquilamente. Costumo perguntar o que meus estudantes compreenderam dos textos teóricos que peço a eles para que leiam e muitas vezes a queixa é de que entenderam muito pouco e de que a dificuldade na leitura foi tremenda. Falta de prática, falta de habitus, falta de referenciais que podem tornar um texto teórico ou literário quase incompreensível. Uma leitura incerta, para retomar a professora citada por Antônio Batista.

No início do curso na Universidade, quando propomos que a leitura seja compartilhada em voz alta, muitos estudantes resistem, às vezes, por vergonha, outras, porque têm muita dificuldade. Se pensamos na leitura de literatura, a questão da oralidade e da presença do corpo na construção de uma compreensão dialógica que vai além do que Zumthor (2014) chama de 
uma "ordem informativa do discurso", que avança em uma performance dramática, advinda da presença sincrônica do emissor da voz e de seu receptor em um momento único, tal leitura em voz alta é uma experiência imprescindível e garante a adesão ao curso e a apropriação, no sentido de incorporação, do que é dito.

A princípio, mais uma das possibilidades didáticas para o ensino de literatura, a leitura em voz alta passou a fazer parte de todas as aulas do CC, pois, por meio dela, é garantido aos estudantes o acesso ao literário e sua compreensão por meio da performance leitora, primeiro da professora e, na sequência, dos próprios estudantes.

\section{Debate interpretativo}

Propostas de leitura em voz alta seguida de debate interpretativo podem receber nomes diversos, a depender do pesquisador que mobilizamos para refletir sobre este tipo de ação, como Lívia Ferreira, Cecília Bajour ou Max Butlen, por exemplo, e funcionam em sala de aula tanto na educação básica como no ensino superior.

A interpretação, entendida como o desvelamento de um sentido escondido no texto, está ligada a uma postura investigativa do sujeito, que conduz a busca de um sentido ou de vários sentidos relativos ao que o texto nos diz sobre a vida ou sobre nós mesmos. Por meio de nossa interpretação, nos expressamos e revelamos muito sobre nossa própria maneira de pensar, nos engajamos como leitores. Como afirma Umberto Eco (1990), não podemos nem conseguimos nos impedir de interpretar todas as coisas, estamos sempre interpretando acontecimentos e textos. Contudo, para que esse exercício possa acontecer em sala de aula, é preciso que se crie uma situação-problema de leitura, com uma verdadeira questão, considerando o texto selecionado; é preciso fazer uma boa leitura do texto; é necessário abrir um espaço de pesquisa sobre o texto a ser lido; escolher procedimentos que favoreçam, num primeiro momento, a reflexão individual e, em um segundo momento, um trabalho coletivo de compreensão e interpretação; identificar um questionamento que leve os alunos a se apropriarem das interpretações possíveis do texto; é fundamental que não imponhamos nossa interpretação, e abramos espaço para as interpretações dos alunos; é preciso organizar a reflexão realizada coletivamente em sala de aula para fazer emergir a diversidade dos modos possíveis de compreensão e interpretação; organizar o confronto de saberes, de estratégias e os resultados que permitem emergir as soluções possíveis; é necessário arbitrar entre os direitos do texto e os direitos do leitor (TAUVERON, 2013), afastando os delírios interpretativos e voltando ao texto para fechar o trabalho. Esse percurso demanda planejamento e só se torna possível se houver 
domínio da leitura do texto, no sentido amplo, e segurança para abrir e contar com a contribuição dos estudantes.

O texto literário é propício a este tipo de trabalho em função de sua ambiguidade, sua multiplicidade de sentidos e, às vezes, as indecisões a que chegam os leitores sobre sua interpretação, sem que se possa decidir qual seria o melhor sentido para um determinado texto. Por isso mesmo, a arbitragem sobre quais são os sentidos possíveis no que tange ao texto literário pode ser muito difícil e precisamos estar preparados para lidar com os imprevistos. Essa dificuldade, contudo, apenas torna o trabalho com a literatura um desafio ainda maior e quando o debate acontece efetivamente, a sensação ao final da aula costuma ser de fruição e de compreensão construída e alcançada.

\section{Diários de leitura}

Seja por meio do debate interpretativo, através da oralização de um texto literário ou do compartilhamento e da defesa de gostos pessoais de leitura, trata-se de criar contextos em que a ação comunicativa é interpessoal, em que o que está em jogo é a interação entre os leitores, a construção de repertórios comuns, o desenvolvimento de comunidades de leitores. Mas esses não são necessariamente movimentos de aprendizagem que se estabeleçam em contextos intrapessoais, que favoreçam processos de interiorização e de apropriação pessoal de práticas desenvolvidas nas salas de aula.

Nesse sentido, percebo que os diários de leitura propõem aos estudantes um espaço pessoal, individual, de manutenção e escrita de um diário, no qual se podem registrar quaisquer associações, observações, sensações, sentimentos etc., que porventura lhes passem pela cabeça enquanto leem um livro. O importante é que o estudante possa engajar-se na escrita de seus pensamentos relativos à leitura proposta ou escolhida.

Nos diários, teremos (MACHADO, 1998) a implicação daquele que escreve o texto, geralmente na primeira pessoa do singular; a presença de referentes privados, sobretudo no que diz respeito aos processos pessoais de leitura; uma estrutura textual em geral fragmentada; um estilo que costuma ser marcado por uma expressividade particular, pessoal e informal; um discurso sincrônico à prática da leitura, tendo em vista que ele é produzido ao mesmo tempo em que ela é realizada. A liberdade para se refletir sobre os enganos, as dificuldades, as mudanças no que se compreende em uma interpretação pessoal de leitura está dada por princípio em um tal exercício. Poder ler esses diários e acompanhar o percurso de leitura dos estudantes pode ser uma poderosa avaliação de como se engajam ou não em um texto, de como 
o interpretam, de como se apropriam dele e pode ser uma experiência valiosa em todos os níveis de ensino.

A título de exemplo, gostaria de apresentar, por fim, apenas dois trechos do diário de Luciana, graduada pela LIL, que atualmente trabalha como assistente administrativa em uma escola pública e se prepara para um concurso para professor da Prefeitura da cidade de Teixeira de Freitas:

\begin{abstract}
$19 / 9 / 17$
É isto, o narrador começa falando mais dele mesmo do que de Macabéa. Gosto de reflexões profundas. Mas, as dele, ou de Clarice são demais - nos dois sentidos da palavra. Não sei se são para o meu bico. Meu corpo e minha mente têm andado cansados nos últimos dias, talvez, isto tenha comprometido minha compreensão. Tentei muito gostar do livro até a página 25,26 ... Foi, difícil. Não detestei. Não amei.
\end{abstract}

\section{1/9/17}

Madame Carlota, apresentada por Glória, jogou as cartas para Maca. Descreveu para ela um futuro cheio de coisas boas, coisas que ela nem sabia que existiam. Só então a nordestina percebeu que a vida poderia ser boa. Saiu da casa da madame cheia de esperanças. Gostei do termo: "grávida de futuro". Acho que foi o único momento em que Maca conheceu a felicidade. Que duraria poucos instantes. Já na saída do beco, ao descer a calçada para atravessar a rua, ela foi atropelada. Nem ali reagiu. Começou a sangrar. Olhar perdido.

Este momento foi A hora da estrela? Ela estava ali, com muita gente ao redor, era o centro das atenções. Desta vez, não estava invisível. Contudo, foi ignorada. Como Clarice, ou S.M.(?) diz no final: "ninguém a ajudou, ninguém nunca a ajudou”.

Por fim, relaciono o trecho a seguir com os brasileiros marginalizados: "Algumas pessoas brotaram no beco não se sabe de onde e haviam se agrupado em torno de Macabéa sem nada fazer assim como antes pessoas nada haviam feito por ela, só que agora pelo menos a espiavam, o que lhe dava uma existência".

\section{Algumas palavras finais}

Seria possível encerrar essas reflexões com a tocante e expressiva apropriação da novela de Clarice Lispector por Luciana. Como esta, várias outras se tornaram possíveis. Tais estudantes escaparam ao destino de se tornarem "leitores incertos" de uma literatura canônica, clássica ou experimental. Eles seguem lendo e pedindo indicações de leitura, seguem buscando o debate e tornando públicas suas interpretações. Meu percurso de formação, as pesquisas que empreendi e o lugar que hoje ocupo em uma Instituição de Ensino Superior no interior do Brasil me possibilitam mobilizar teoria e investigações na colocação em prática de um objetivo que parece ser primordial na formação de futuros professores de Língua Portuguesa: a formação do leitor literário. Constituem ações imprescindíveis no ensino superior que se propõe a tal desafio: investigar as práticas de leitura dos licenciandos; construir com eles um repertório de leitura; trabalhar no sentido de formar uma comunidade de leitores; apresentar a eles obras literárias 
em que o estranhamento e o incômodo possam surgir, em que uma linguagem articulada de outra forma que não a do cotidiano, com estruturas narrativas mais complexas e de difícil apreensão, possa ser compreendida e possa fazer sentido; oferecer maneiras de se registrar o que se sente e se pensa quando se lê literatura; apresentar maneiras de se externar e de se interpretar um texto ambíguo, todas essas ações tornam-se imprescindíveis no ensino superior de um curso que se propõe a tal desafio. Ou seja, trata-se de inserir no currículo do ensino superior de modo explícito os objetivos de formação de leitores literários e do estabelecimento de práticas de leitura literária diversas em sala de aula, para que o ensino da literatura possa, então, efetivamente acontecer.

\section{Referências}

BATISTA, A. A. G. Os professores são não-leitores? In: MARINHO, M.; SILVA, C. S. R. (orgs.). Leituras do professor. Campinas: Mercado de Letras, 1988.

BOURDIEU, P. A economia das trocas simbólicas. São Paulo: Perspectiva, 2005.

BOURDIEU, P. A distinção. Porto Alegre/São Paulo: Zouk/Edusp, 2006.

BOURDIEU, P.; CHARTIER, R. O sociólogo e o historiador. Tradução de Guilherme João de Freitas Teixeira. Belo Horizonte: Autêntica, 2011.

BRUNER, J.; WEISSER, S. A invenção do ser: a autobiografia e suas formas. In: OLSON, D. R.; TORRANCE, N. Cultura escrita e oralidade. São Paulo: Ática, 1995.

CHARTIER, R. A história cultural. Entre práticas e representações. Lisboa: Difusão Editorial, 1988.

CHARTIER, R. A aventura do livro. Do leitor ao navegador. São Paulo: Unesp/Imprensa Oficial do Estado, 1999.

CITELLI, A. Comunicação e educação: a linguagem em movimento. São Paulo: SENAC Editora, 2004.

ECO, U. Os limites da interpretação. São Paulo: Editora Perspectiva, 1990.

FERREIRA, L. A convivência com os textos. São Paulo: FFCLA, 1970.

FREDERICO, E. Y.; OSAKABE, H. PCNEM - Literatura. Análise crítica. In: MEC/SEB/DEPARTAMENTO DE POLÍTICAS DE ENSINO MÉDIO. Orientações Curriculares do Ensino Médio. Brasília, 2004.

LAJOLO, M. Usos e abusos da literatura na escola. Bilac e a literatura escolar na República Velha. Rio de Janeiro: Globo, 1982. 
LEBRUN, M. A emergência e o choque das subjetividades de leitores do maternal ao ensino médio graças ao espaço interpretativo aberto pelos comitês de leitura. In: ROUXEL, A.; LANGLADE, G.; REZENDE, N. L. (orgs.). Leitura subjetiva e ensino de literatura. São Paulo: Alameda, 2013.

MACHADO, A. R. O diário de leituras: a introdução de um novo instrumento na escola. São Paulo: Martins Fontes, 1998.

OLIVEIRA, G. R. O professor de português e a literatura: relações entre formação, hábitos de leitura e práticas de ensino. São Paulo: Alameda, 2013a.

OLIVEIRA, G. R. As práticas de leitura literária de adolescentes e a escola: tensões e influências. 2013. 377 p. Tese (Doutorado em Linguagem e Educação) - Faculdade de Educação, Universidade de São Paulo, São Paulo, 2013b.

RAZZINI, M. de P. G. O espelho da nação: a Antologia Nacional e o ensino de português e de literatura (1838-1971). 2000. 442p. Tese (doutorado) - Universidade Estadual de Campinas. Instituto de Estudos da Linguagem, Campinas, SP. Disponível em:

<http://www.repositorio.unicamp.br/handle/REPOSIP/270144>. Acesso em: 29 set. 2020.

ROCCO, M. T. F. Literatura/ensino: uma problemática. São Paulo: Ática, 1981.

VIEIRA, A. Análise de uma realidade escolar: o ensino de literatura no $2^{\circ}$ grau, hoje. 1988. 317p. Tese (Doutorado em Educação) - Faculdade de Educação da Universidade de São Paulo, São Paulo. Disponível em: <https://www.teses.usp.br/teses/disponiveis/48/48134/tde07102008-101148/publico/DissertacaoGabrielaRodella.pdf>. Acesso em: 29 set. 2020.

TAUVERON, C. Direitos do texto e direitos dos jovens leitores: um equilíbrio instável. In: ROUXEL, A.; LANGLADE, G.; REZENDE, N. L. (orgs.). Leitura subjetiva e ensino de literatura. São Paulo: Alameda, 2013.

UNIVERSIDADE FEDERAL DO SUL DA BAHIA (UFSB). Projeto Pedagógico de Curso: Licenciatura Interdisciplinar em Linguagens e suas Tecnologias. Itabuna/Porto Seguro/Teixeira de Freitas: 2016.

ZILBERMAN, R. Segundo grau, vestibular e literatura. In: ZILBERMAN, R. A leitura e o ensino de literatura. 2. ed. São Paulo: Contexto, 1988.

ZUMTHOR, P. Performance, recepção, leitura. São Paulo: Cosac Naify, 2014.

Recebido em: 18/05/2020 Aceito para publicação em: 18/08/2020 